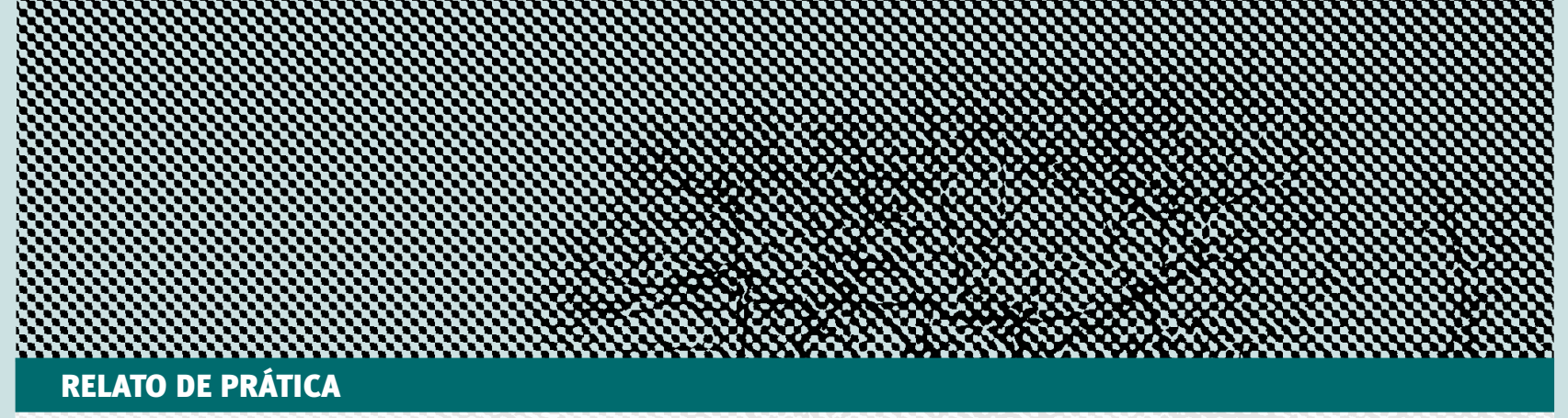

\title{
Que relações de cooperação são possiveis entre a família e a escola?
}

\author{
ABDALAZIZ DE MOURA*
}

\section{O Serviço de Tecnologia Alternativa - SERTA vem, desde} 1993, tentando aproximar a família da escola e vice-versa. Muito se tem descoberto nessa iniciativa. 0 objetivo deste texto é partilhar com os leitores as experiências e refletir sobre elas.

\section{Uma relação de desconfiança}

Quando o SERTA insistia na aproximação da escola com as famílias, numa proposta de Educação do Campo, encontrava uma resistência quase instintiva da parte das professoras. Era comum a professora dizer que os pais não viriam à escola, não atenderiam ao convite. Por trás dessa desconfiança, estava uma prática antiga de a família ser chamada à escola somente em casos de reclamação a respeito do filho ou filha.

Tratava-se de algum comportamento indesejado que a professora se via sem condição de resolver sozinha; então, chamava a família para reclamar, para cobrar, até mesmo para punir o filho. Essa atitude virou uma cultura, de modo que ser chamado para comparecer à escola já deixava a família de "orelha em pé”:

\section{O que houve com meu filho?}

O ele aprontou dessa vez?

Podia não ser nada disso, podia ser diferente, mas o pai ou mãe já iam inseguros.

Além disso, no meio rural, muitas mães e pais não têm o domínio das letras, da escrita, da oralidade, como a escola tem. Vir discutir algum assunto na escola é como vir em desvantagem:

* ABDALAZIZ DE MOURA é presidente do Serviço de Tecnologia Alternativa - SERTA. E-mail: 〈abdalazizdemoura@hotmail.com〉; tel: 081 9299.7775, Centro Tecnológico da Agricultura Familiar - CTAF 087.3932.5008.

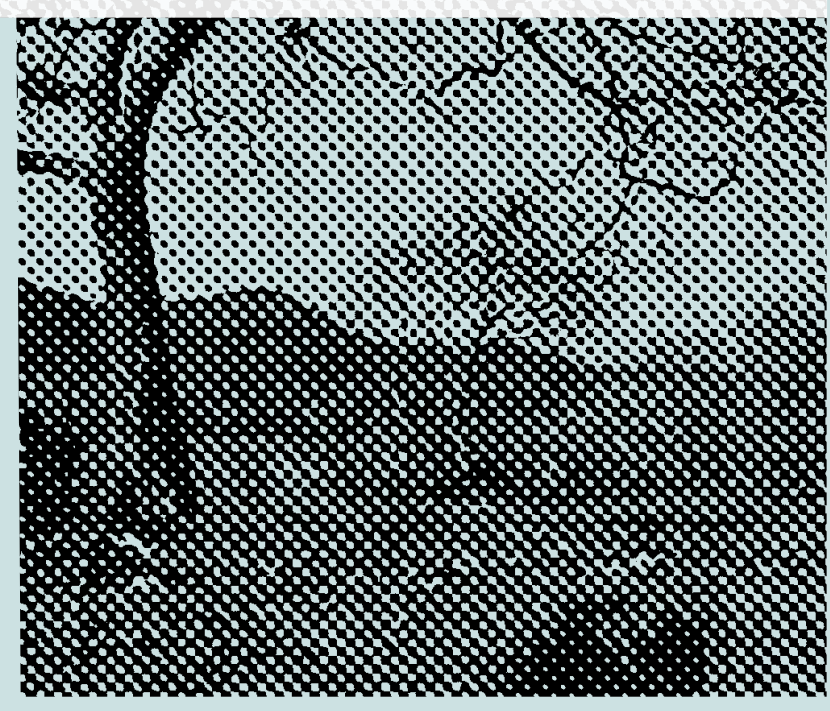

As professoras sabem mais, falam melhor, eu lá entendo disso!

Os meios de comunicação, os modos de travar uma conversa, os professores dominam muito melhor que os pais. Também enxergam a escola como se fosse uma autoridade que os convoca para algum "puxão de orelhas".

Um bilhete da escola vem carregado de cobrança: nota, comportamento, atraso de pagamento, alguma taxa. Exceção para os dias das mães e dos pais. Nesses dias, eles vêm com gosto, com prazer, pois sabem que vão ser homenageados, que as atenções se voltam para eles, que a escola prepara alguma surpresa agradável com seus filhos, para eles. Há um clima, uma ambiência agradável, favorável à presença e ao encontro.

\section{Um olhar mais aguçado}

No debate com as professoras, o SERTA partia dessa experiência gostosa que é ser convidado para uma festa em sua homenagem. Os pais se aproximam quando percebem que são importantes, quando sabem que o que lhes espera é algo bom! Distanciam-se quando desconfiam! Não sabem se vão ser chamados à atenção ou 
se vão ser elogiados! Há três coisas a considerar: a forma de convidar, a finalidade do convite e o papel que se atribui à família.

\section{A forma do convite}

\section{Na Proposta de Educação trabalhada pelo SERTA, qual é} a forma de convidar? Inicialmente, por meio de uma ampla mobilização dentro e fora da escola, com os alunos participando da redação do convite, com os alunos informados e preparados para o que vai acontecer no encontro, organizando equipes entre os que conhecem a mesma família, para reforçar o convite, ampliando o convite a outras lideranças comunitárias, tais como o agente comunitário de saúde, o dirigente da associação, do sindicato, do clube...

Os estudantes vão vivenciando outra experiência: convidar a família já passa a ser um interesse deles e não só da escola. Já se sentem comprometidos com o resultado da mobilização. A professora aproveita as oportunidades para lembrar o dia, a hora, confirmar com o aluno se já falou, se os pais já deram resposta. Tanto os estudantes quanto as famílias começam a se sentir valorizados pela forma de operacionalizar o convite, uns já reforçam aos demais para que não faltem.

\section{A finalidade do convite}

\section{A escola, se não é, poderia e deveria ser um centro pro-} dutor e difusor de conhecimento. Ela pode se propor a esse fim, mais do que qualquer outra instituição, pela tradição, pela legitimação, pelo reconhecimento, pela capilaridade e presença nas menores comunidades. E, principalmente, pelo sistema e rede nos quais se insere.

A escola tem uma atividade diária, consagra o mínimo de quatro horas por dia ao estudo, usa avaliação, é progressiva, é financiada para esse fim. Porém, é fácil reconhecer que ela não é a única instituição que produz conhecimento.

Qualquer comunidade humana vive produzindo e necessitando de conhecimento. Se essa comunidade é rural ou urbana, da periferia ou do centro da metrópole, se pretende se desenvolver, só vai ser possível se mais conhecimentos forem construídos pelos seus habitantes. Mas não é só de conhecimento que a escola e as comunidades vivem e precisam. Necessitam tanto de valores e de crenças como de novas relações pessoais, institucionais e de produção.

No meio rural e no campo, ou as comunidades incorporam, resgatam, assimilam, constroem novos conhecimentos, valores, relações, ou não saem do patamar no qual se encontram. Só que conhecimentos, valores, relações, muita gente que vive nas comunidades já tem de forma social, prática, o suficiente para sobreviver no seu dia-a-dia. Mas, na sociedade contemporânea, impôs-se a convicção de que esse tipo de conhecimento não é importante, nem muito verdadeiro. 0 conhecimento importante é o científico.

Essa convicção amplia o fosso entre a escola e a comunidade. Na hora em que ambos começarem a entender que

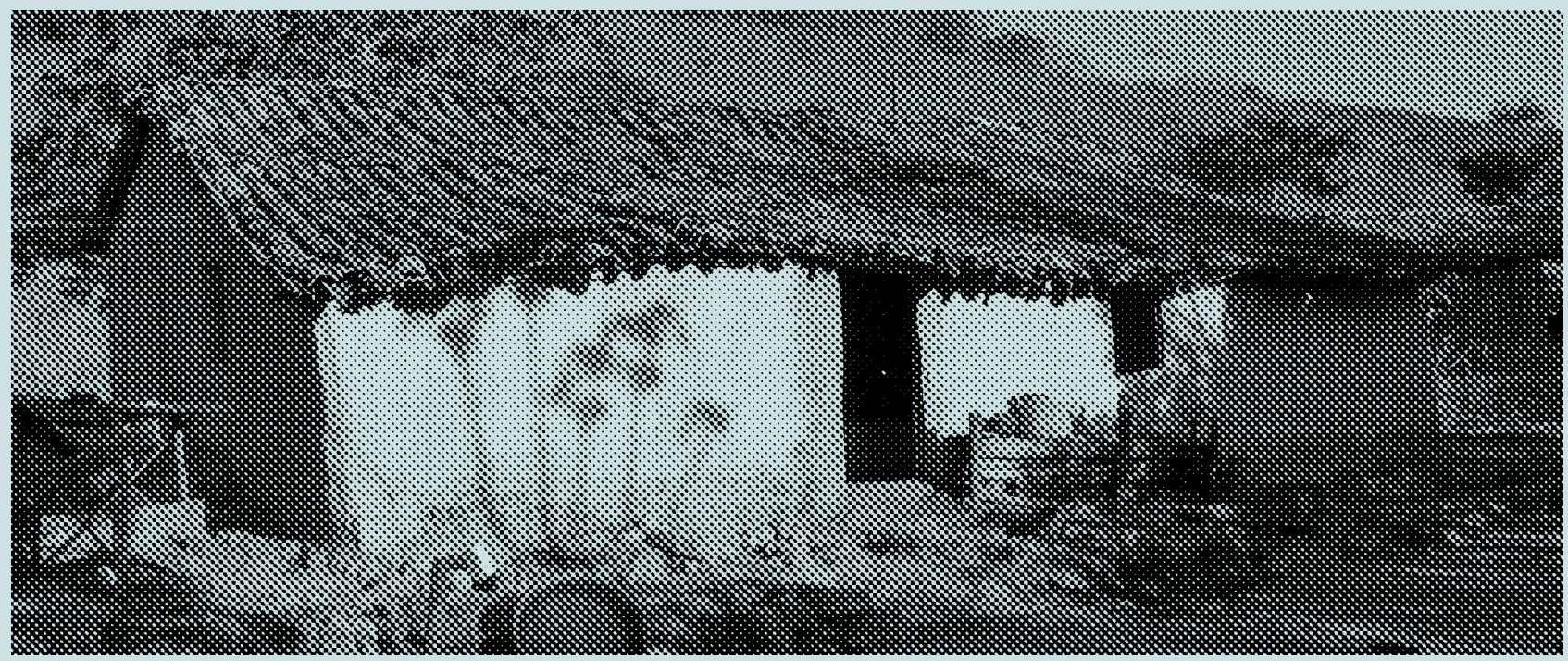


os conhecimentos são de diversos tipos e atendem a necessidades diferentes, vão perceber que na comunidade há quem domine conhecimentos. E que poderiam ensinar na escola, compartilhar, num ambiente mais legitimado e reconhecido, os conhecimentos que têm. Quando isso acontece, muda radicalmente a relação entre a escola e as famílias.

A escola vai entender que não sabe ensinar a cozinhar, tomar conta de criança, plantar, cuidar dos animais, manejar o roçado e o criatório, fazer cerca, vacinar os animais, fazer uma feira, dividir o dinheiro do mês, tirar empréstimo, vender, organizar uma associação, preparar carne de sol, fazer queijo, manteiga. No entanto, são conhecimentos imprescindíveis que uma comunidade rural precisa ter, entre tantos outros.

Esses conhecimentos, considerados práticos, assimilados pela vivência e pelo trabalho no processo de desenvolvimento, precisam elevar seu patamar, chegar a um nível mais técnico, mais científico. Esse, por sua vez, precisa ser dominado amplamente pelas pessoas da comunidade, como acontece com a leitura, a escrita, a matemática e a informática.

Se não houver esse avanço, a comunidade não sai do patamar em que se encontra. Os criatórios dos animais vão ficar sempre em um nível precário, pois os jovens que foram para a escola nada trouxeram para o avanço deles. Os filhos se formam, concluem o ensino básico e os pais continuam cuidando dos animais do mesmo jeito de quando seus filhos não estavam na escola.

Em outras palavras, a escola não trouxe para a família uma contribuição científica, técnica, para melhorar o seu rebanho. Nem valorizou o que as famílias já têm, nem acrescentou o novo que lhes falta. 0 pai, a mãe, as lideranças locais estão à margem do processo, como se o papel da escola fosse outra coisa, como se o conhecimento que ela cultiva fosse de outra ordem e natureza, como se fosse para outro público. Os filhos são preparados para abandonar essa família, ir para a cidade, manejar outros conhecimentos, cuidar de outros valores e relações. Essa família está condenada a se manter no campo, sobreviver só com os conhecimentos já incorporados ao senso comum!

Evidente que, com esse pressuposto, a parceria entre a família e a escola não acontece, pois, o que está por trás é o resquício, alimentado pela cultura, de uma relação entre o ignorante e o sabido, em que ambas aceitam os papéis tradicionalmente atribuídos pela sociedade a uma e a outra. Uma domina o saber científico e técnico (e assim mesmo, com muitas reservas!) e a outra, o saber prático. Ambas estão bem no lugar e no papel que exercem.

\section{0 papel que atribuem à escola e à família}

Se esses papéis são para permanecer, nem adianta falar de cooperação entre escola e família, porque ela já está contaminada e viciada. Já vem com vírus e pode estragar. Uma já vai se apresentar melhor do que a outra, com mais autoridade sobre a outra, uma avaliando a outra, uma sendo sujeito e outra sendo objeto, uma conduzindo o processo e outra se adaptando. São relações de subordinação e não de cooperação.

\section{Construindo novas relações}

\section{As comunidades são como as pessoas: elas precisam} evoluir, manter-se e perpetuar-se. Para isso, elas se apropriam do patrimônio construído pela sociedade. As formas de apropriação e o nível variam muito de lugar para lugar. Mas não se pode negar que as comunidades precisam cada vez mais de usar conhecimentos e cultivar valores e relações. Não podemos aceitar a idéia de que o filho chegou à universidade e a propriedade da família não tenha saído do Fundamental I.

Podemos imaginar, então, um centro produtor e difusor desses conhecimentos e valores: é a escola interagindo com as famílias. Os alunos participando da construção de conhecimentos úteis para melhorar a sua propriedade e o ganho de sua família, em que o nível de aproveitamento dos recursos da propriedade se amplia à medida que o filho avança na escola.

Se não acontecer assim, para que serve o conhecimento? Se ele não repercute nas casas, se não traz conseqüência, se não é útil aqui e agora, se não melhora a vida, o meio ambiente, a natureza, os animais, a vegetação, a água, a cidadania, o direito, a política, então, para que serve? Se servir para a vida, a escola passa a exercer a função de um grande laboratório, aberto à participação dos mais diversos autores, atores e agentes sociais, aos técnicos da saúde, da agricultura, às lideranças, aos pais e às mães de alunos.

Torna-se uma escola aberta não só nos finais de semana, não só com suas instalações, quadra de esporte e laboratório de informática, e sim com o seu projeto 


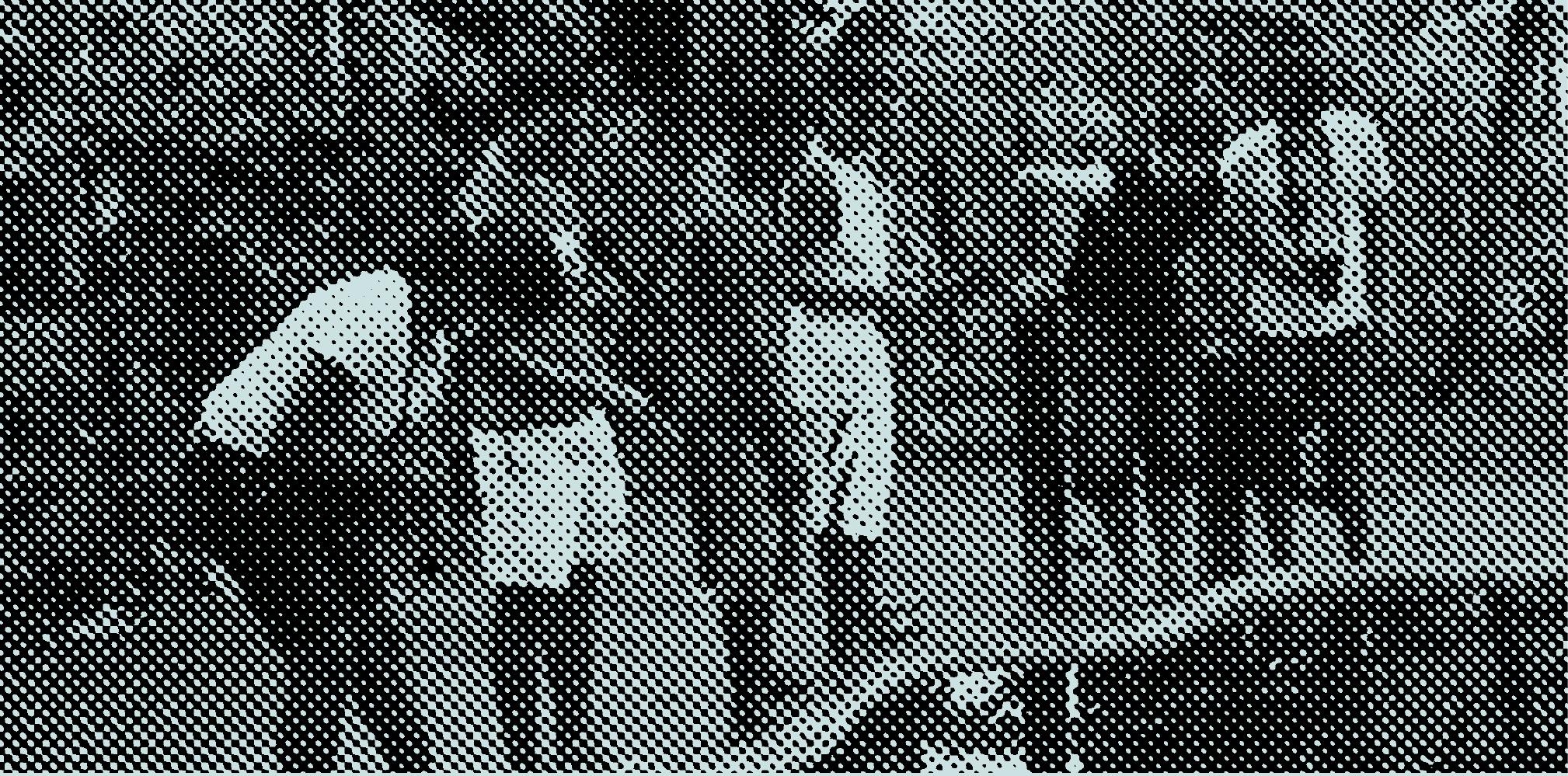

político-pedagógico. Os pais passam a se sentir membros da escola, mesmo que não estejam no EJA, porque interagem diretamente com seus filhos na propriedade. Os professores circulam nas propriedades e os familiares circulam nas escolas, numa relação de parceria, de intercâmbio, de troca de conhecimentos, experiências. A escola passa a pulsar com as demandas e necessidades da comunidade e vice-versa.

Estou escrevendo este artigo na mesma semana que estão passando pelas minhas mãos alguns projetos dos municípios para concorrer ao Selo Unicef. É gratificante perceber que as escolas vivenciaram, experimentaram o sabor de uma escola pulsando com a comunidade. Seu desafio vai ser incorporar essa oportunidade no dia-a-dia da escola, como projeto político-pedagógico e não só para concorrer ao selo.

\section{Concluindo}

\section{Escolas com essa relação com a comunidade existem,} têm nome e endereço: as que usam a Peads - Proposta Educacional de Apoio ao Desenvolvimento Sustentável, criada pelo Serviço de Tecnologia Alternativa - Serta. Dez dessas escolas, no estado de Pernambuco, estão vivenciando um processo de formação e capacitação em que participam familiares, gestores, educadores, alunos, e todos se envolvem nas práticas e conhecimentos úteis para as famílias.

Esse trabalho articula-se com o Centro Tecnológico da Agricultura Familiar - CTAF, com sede em Glória do Goitá (Zona da Mata) e Ibimirim (Semi-árido), nas quais os sujeitos sociais recebem a primeira formação de dois dias; a partir daí, as formações na escola passam a contar sempre com alunos, familiares e educadores. 0 Unicef está patrocinando esse projeto, com uma rede de dez escolas, em dez municípios, e a Fundação Kellogg apóia a rede em mais dez escolas de dois municípios.

Pais e mães foram convocados a participar pelas suas qualidades, seus valores e seus saberes. As relações com a escola não são mais as mesmas; em casa, a relação com os filhos que estudam mudou, eles discutem e fazem juntos as ações discutidas na escola e na propriedade.

\section{REFERÊNCIAS}

MOURA, Abdalaziz de. Princípios e fundamentos da Proposta Educacional de Apoio ao Desenvolvimento Sustentável, uma proposta que revoluciona o papel da escola diante das pessoas, da sociedade e do mundo. 2. ed. Recife: 2003 MOURA, Abdalaziz de; VICENTE, Ilza André; SILVA, Socorro; MARIA, Iramaí (Org.) Múltiplos olhares de uma caminhada pedagógica: a Proposta Educacional de Apoio ao Desenvolvimento Sustentável - Peads. Recife: 2006.

MOC; SERTA, UEFS. Educação rural, sustentabilidade do campo. Feira de Santana: 2003.

CEE; MEC. Diretrizes Curriculares para a Educação Básica nas Escolas do Campo. BSB, 2002.

DAMASCENO, Maria Nobre. A construção do saber social pelo camponês na sua prática produtiva e política. In: Sociedade civil e educação. Campinas: Papirus, 1991. p.35-56 
